\title{
Comparative kinematic analysis of the baseball pitching motions of high school athletes in relation to pitching conditions
}

\author{
Sang-Jin Yoon', Kazunori Irie', Dae-Young Kim², Tae-Jin Park ${ }^{2 * *}$ \\ ${ }^{1}$ Graduate School of Health and Sport Science, Nippon Sport Science University, Tokyo, Japan \\ ${ }^{2}$ Department of Sports Healthcare, College of Humanities \& Social Sciences, Inje University, Gimhae, Korea
}

To analyze changes in pitching motions in relation to pitching conditions during practice versus game comparatively, seven high school overthrowing pitchers served as subjects in this study, who then performed pitches in various conditions. Data were processed using the statistical analysis program SPSS 21.0, and the moving distances and angles of the joints at the point of ball release were analyzed using repeated measurements one-way analysis of variance, followed by Bonferroni post hoc tests. Statistical significance was determined at $P<0.05$, and the following conclusion was obtained. According to the pitching conditions, the elbow joint was lengthened, and the torso leaned towards the nonpitching arm during pitching. Further, the pitching stride in- creased, causing the forward transfer of the landing foot and the pitching hand. Based on these observations, it is important to establish a pitching training method that minimizes inconsistency in pitching motions by simulating game-like conditions during pitching practices and developing various training programs. Further investigation is required for a comprehensive mechanical analysis of muscle usage and damage in pitching motions in relation to various pitching conditions.

Keywords: Baseball, Pitcher, Pitching conditions, Three-dimensional analysis

\section{INTRODUCTION}

Since the first World Baseball Classic in 2006, not only has baseball become a sport that is greatly enjoyed worldwide, but it has also been considered a national sport in the United States, Japan, South Korea, and Taiwan; the importance of research on the biomechanical motions and injury prevention in baseball has been increasing. Generally, the types of motions in baseball are pitching, batting, running, and catching, and injuries occur most frequently during pitching and running (Queale et al., 2001). Pitching motions are generally categorized into four types, over-throw, three-quarter, side-throw, and under-throw, with overthrow as the most widely used pitching method, since it allows for a fastball and is associated with low risk for injuries (Albright et al., 1978; Braatz and Gogia, 1987; Matsuo et al., 2001).
A pitching motion occurs in a sequence of six steps: wind-up, stride, arm cocking, arm acceleration, arm deceleration, and follow-through (Fleisig et al., 1996). Kinematic and kinetic analyses are conducted in accordance with these steps (Huang et al., 2010; Stodden et al., 2005; Whiteley, 2007; Yamada et al., 2013). According to studies on injuries in the upper extremities, such as the shoulders and elbows, which are the most common injury sites in baseball motions (Collins and Comstock, 2008; Conte et al., 2001; Dick et al., 2007; Fleisig et al., 1999; Lyman et al., 2002; Posner et al., 2011; Wright et al., 2007), baseball injuries are categorized into "misuse," which is a type of injury caused by imperfect pitching techniques (Davis et al., 2009), and "overuse," which is a type of injury caused by excessive practicing, despite accurate pitching techniques (Cowderoy et al., 2009; Hutchinson and Ireland, 2003; Parks and Ray, 2009; Rizio and Uribe, 2001). These stud-
${ }^{*}$ Corresponding author: Tae-Jin Park (iD https://orcid.org/0000-0002-6939-236X Department of Sports Healthcare, College of Humanities \& Social Sciences, Inje University, 197 Inje-ro, Gimhae 50834, Korea

Tel: +82- 55-320-3172, Fax: +82-55-320-3545, E-mail: jin74tae@naver.com Received: April 10, 2018 / Accepted: May 6, 2018
This is an Open Access article distributed under the terms of the Creative Commons Attribution Non-Commercial License (http://creativecommons.org/licenses/by-nc/4.0/) which permits unrestricted non-commercial use, distribution, and reproduction in any medium, provided the original work is properly cited. 
ies on pitching-related injuries were conducted, based on the assumption that the pitching motions in a bullpen during practice are identical to those during a baseball game, where various external factors are present, such as the batter, catcher, and crowd, without taking into account the specific environment and conditions in which actual pitching occurs during a baseball game. However, the specific environment and conditions of a game involve various factors, such as the presence or absence of a mound, pitcher, presence of a catcher, and location of the batter, and can influence pitching motions in contrast to a simple pitching practice. It has been reported that the muscle fatigue of the pitcher during a pitching simulation affects the pitching motions (Escamilla et al., 2007), and depending on the type of the ball used and the number of pitches, the risk of injuries in the upper extremities, specifically the shoulders and elbows, can increase (Lyman et al., 2002). According to a study on injuries of baseball players (Dick et al., 2007), the risk of injuries increases by 3 fold during a baseball game compared with that during practice.

However, further investigation is required to understand the environment-associated differences between pitching motions during a baseball game and practice. Thus, this report focused on injury prevention via a comparative analysis of pitching motions during a baseball game versus during practice by simulating corresponding conditions for each situation.

\section{MATERIALS AND METHODS}

\section{Subjects}

The subjects of this study were composed of right-handed, overthrowing high school pitchers with a minimum of 3 years of experience. The purpose of the study and the experimental details and procedure were explained to the subjects, and seven of the subjects who signed the research participant consent form were selected for the study. The average age, height, and weight of the study subjects were $18.0 \pm 4.3$ years, $180.1 \pm 4.3 \mathrm{~cm}$, and $75.1 \pm$ $7.5 \mathrm{~kg}$, respectively.

\section{Experimental setup and procedure}

The experiments were conducted in the outdoor baseball field at Sungkyunkwan University, and the temperature was $18^{\circ} \mathrm{C}-$ $24^{\circ} \mathrm{C}$ with clear skies. The selected pitching method was overthrow, and the pitching motion at the point of ball release (BR) during the acceleration step, where muscular exertion is at the highest, was compared and analyzed (Fleisig et al., 1996; Jobe et al., 1983; Jobe et al., 1984). The pitches of all subjects were ex- amined in a set position (Dun et al., 2008; Keeley et al., 2012).

The experimental setup was composed of three conditions: (a) the pitches take place in a manner identical to those in a bullpen with a mound, without a batter and speed gun (condition 1, C1); (b) the pitches are assessed using a speed gun and performed in a manner identical to that in a baseball game, with a mound, left-handed batter and catcher (condition 2, C2); and (c) the pitches occur in the same conditions as in $\mathrm{C} 2$ but with a right-handed batter (condition 3, C3).

The subjects were required to perform five power pitches and to recreate the psychological state as best as they could that arises when they face the bottom half of the ninth inning with two strikes and three balls during an actual baseball game.

\section{Data collection and analysis}

To generate data from a three-dimensional (3D) kinematic analysis of motions, markers were attached on the body of the subjects, and to improve the accuracy of the measured angles of the joints, the subjects wore triangular swimmers for sports. The central reference point $(\mathrm{P})$ was set at the center of a $30 \times 16-\mathrm{cm}$ pitcher's plate. The pitching motions were filmed at a sampling frequency of $240 \mathrm{~Hz}$, and videos were processed using a 3D video motion analysis software (Frame-DIASIV, DKH Co., Tokyo, Japan) to analyze the biomechanical movements of the upper extremities, lower extremities, and pelvis at the point of $\mathrm{BR}$, as observed in frontal and right lateral views (Fig. 1). Statistical analysis was conducted via repeated measurements one-way analysis of variance using IBM SPSS Statistics ver. 21.0 (IBM Co., Armonk, NY, USA), and the Bonferroni method was used for post hoc tests. Values were determined to be statistically significant if the $P$-value was less than 0.05 .

\section{RESULS}

\section{Moving distances of the joints in relation to the pitching conditions}

The ranges of joint movements at the point of BR during pitching in relation to the distinct conditions are illustrated in Table 1 and Fig. 1. The comparative analysis of the joint movements with respect to the pitching conditions showed that the moving distance of the joints for $\mathrm{D} 1$ was $33.18 \pm 10.89 \mathrm{~cm}$ during practice and $33.97 \pm 11.78 \mathrm{~cm}$ (left-handed batter) and $31.36 \pm$ $10.97 \mathrm{~cm}$ (right-handed batter) during a game, with a significant difference $(P=0.005)$ among the different experimental conditions; there was a shorter moving distance in $\mathrm{C} 3$ than in $\mathrm{C} 2$. The mov- 

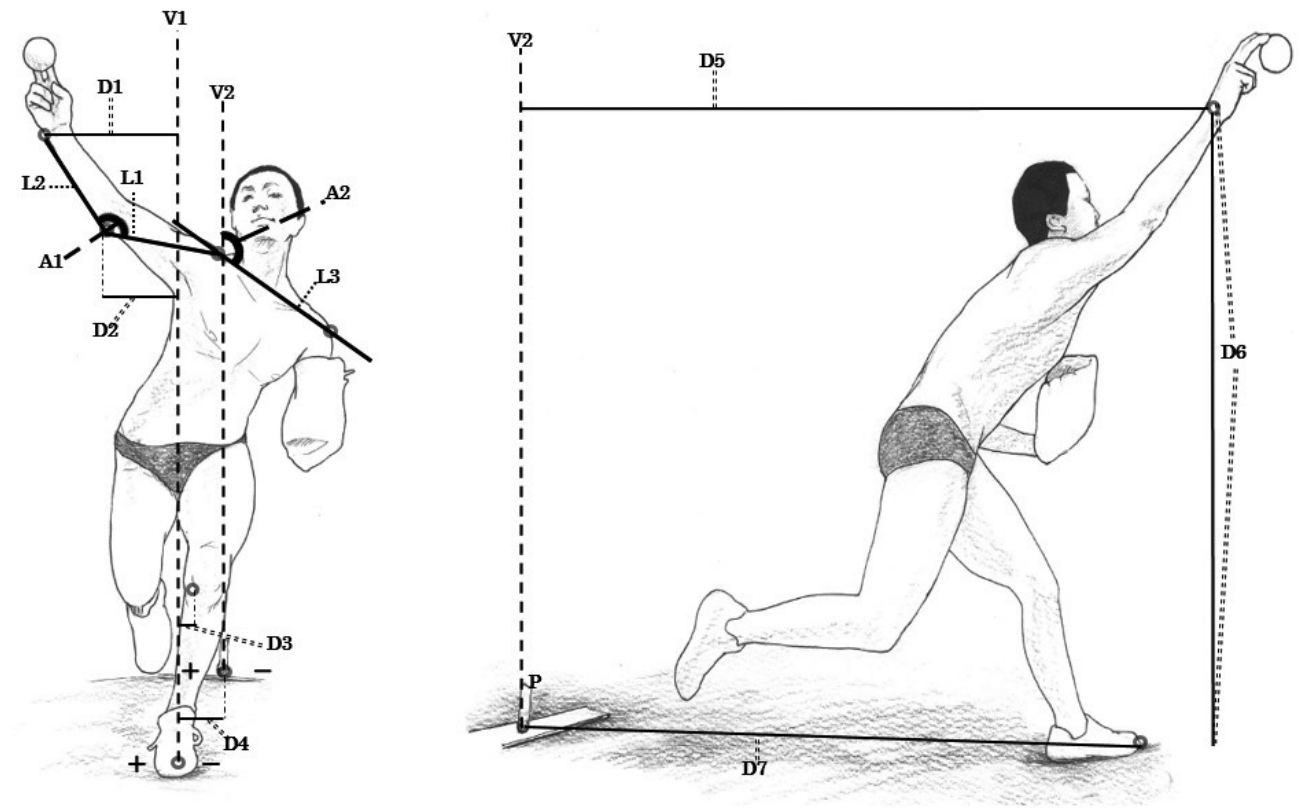

Fig. 1. Definition of kinematic variables. D1, distal end of the left third metatarsal-right ulnar styloid horizontal distance; D2, distal end of the left third metatarsal-right lateral humeral epicondyle horizontal distance; D3, distal end of the left third metatarsal-left medial femoral epicondyle horizontal distance; D4, midpoint of pitcher's plate (P)-distal end of the left third metatarsal horizontal distance; D5, midpoint of pitcher's plate-right ulnar styloid horizontal distance/height; D6, right ulnar styloid vertical distance/height; D7, midpoint of pitcher's plate-right medial malleolus distance/height; L1, a line connecting right internal superior tip of acromion and right lateral humeral epicondyle; L2, a line connecting right lateral humeral epicondyle and right ulnar styloid; L3, a line connecting right and left internal superior tip of acromion; V1, vertical line through distal end of the left third metatarsal at the ball release; V2, vertical line through midpoint of pitcher's plate (P); +, right; -, left; A1, right internal superior tip of acromion-right internal humeral epicondyle-right ulnar styloid angle; $A 2$, right-left internal superior tip of acromion tilt angle.

Table 1. Distance movement of joint point according to pitching conditions

\begin{tabular}{|c|c|c|c|c|c|}
\hline Distance & Condition 1 & Condition 2 & Condition 3 & F-value & Bonferroni \\
\hline $\mathrm{D} 1(\mathrm{~cm})$ & $33.18 \pm 10.89$ & $33.97 \pm 11.78$ & $31.36 \pm 10.97$ & $8.422^{* *}$ & $\mathrm{C} 3<\mathrm{C} 1, \mathrm{C} 2$ \\
\hline $\mathrm{D} 2(\mathrm{~cm})$ & $19.59 \pm 6.01$ & $20.12 \pm 6.84$ & $18.57 \pm 6.79$ & 2.685 & - \\
\hline $\mathrm{D} 3(\mathrm{~cm})$ & $-6.24 \pm 4.17$ & $-6.34 \pm 3.83$ & $-6.44 \pm 3.81$ & 0.056 & - \\
\hline D4 (cm) & $20.77 \pm 13.21$ & $22.52 \pm 12.70$ & $21.87 \pm 13.77$ & 2.173 & - \\
\hline D5/HT (\%) & $96.85 \pm 6.69$ & $97.84 \pm 6.21$ & $99.59 \pm 6.18$ & $20.227^{* * *}$ & $\mathrm{C} 1<\mathrm{C} 2<\mathrm{C} 3$ \\
\hline D6/HT (\%) & $87.80 \pm 4.12$ & $87.49 \pm 4.37$ & $88.05 \pm 4.64$ & 1.559 & - \\
\hline $\mathrm{D} 7 / \mathrm{HT}(\%)$ & $98.31 \pm 4.57$ & $99.59 \pm 4.54$ & $100.94 \pm 5.64$ & $11.862^{* *}$ & $\mathrm{C} 1<\mathrm{C} 2<\mathrm{C} 3$ \\
\hline
\end{tabular}

Values are presented as mean \pm standard deviation.

D1, distal end of the left third metatarsal-right ulnar styloid horizontal distance; D2, distal end of the left third metatarsal-right lateral humeral epicondyle horizontal distance; D3, distal end of the left third metatarsal-left medial femoral epicondyle horizontal distance; D4, midpoint of pitcher's plate (P)-distal end of the left third metatarsal horizontal distance; D5, midpoint of pitcher's plate-right ulnar styloid horizontal distance/height; D6, right ulnar styloid vertical distance/height; D7, midpoint of pitcher's plate-right medial malleolus distance/height; $\mathrm{C}$, condition; $\mathrm{HT}$, height.

${ }^{* *} P<0.01$. ${ }^{* * *} P<0.001$.

ing distance of the joints for $\mathrm{D} 2$ was $19.59 \pm 6.01 \mathrm{~cm}$ during practice and $20.12 \pm 6.84 \mathrm{~cm}$ (left-handed batter) and $18.57 \pm 6.79 \mathrm{~cm}$ (right-handed batter) during a game, indicating no significant differences among the three experimental conditions. The moving distance of the joints for $\mathrm{D} 3$ was $-6.24 \pm 4.17 \mathrm{~cm}$ during practice and $-6.34 \pm 3.83 \mathrm{~cm}$ (left-handed batter) and $-6.44 \pm 3.81 \mathrm{~cm}$ (right-handed batter) during a game, showing no significant differences among the three experimental conditions.

The proportion of the joint moving distance to the height for D5 was $96.85 \% \pm 6.69 \%$ during practice and $97.84 \% \pm 6.21 \%$ (left-handed batter) and $99.59 \% \pm 6.18 \%$ (right-handed batter) during a game, with a significant difference $(P=0.000)$. The ob- 
Table 2. Angle of shoulder and elbow according to pitching conditions

\begin{tabular}{lllllc}
\hline Angle & Condition 1 & Condition 2 & Condition 3 & F-value & Bonferroni \\
A1 & $135.66 \pm 8.46$ & $136.62 \pm 8.66$ & $136.82 \pm 7.97$ & 1.315 & - \\
A2 & $119.73 \pm 12.58$ & $120.37 \pm 13.57$ & $121.96 \pm 13.01$ & $5.850^{*}$ & C1<C2, C3
\end{tabular}

Values are presented as mean \pm standard deviation.

$A 1$, right internal superior tip of acromion-right internal humeral epicondyle-right ulnar styloid angle; $A 2$, right-left internal superior tip of acromion tilt angle; $\mathrm{C}$, condition.

${ }^{*} P<0.05$.

tained values decreased in the order of $\mathrm{C} 3, \mathrm{C} 2$, and $\mathrm{C} 1$. The proportion of the joint moving distance to the height for $\mathrm{D} 6$ was $87.80 \% \pm 4.12 \%$ during practice and $87.49 \% \pm 4.37 \%$ (lefthanded batter) and $88.05 \% \pm 4.64 \%$ (right-handed batter) during a game, indicating no significant differences.

The proportion of the joint moving distance to the height for D7 was $98.31 \% \pm 4.54 \%$ during practice and $99.59 \% \pm 4.54 \%$ (left-handed batter) and $100.94 \% \pm 5.64 \%$ (right-handed batter) during a game, with a significant difference $(P=0.001)$; the obtained values in $\mathrm{C} 1$ were lower than those in $\mathrm{C} 2$ and $\mathrm{C} 3$.

\section{Angles of the shoulders and elbows during pitching in relation to the conditions}

The measured angles created by the shoulders and elbows at the point of BR during pitching in relation to the distinct conditions are illustrated in Table 2 and Fig. 1. In the comparative analysis of the distinct pitching conditions, the angle of the shoulders and elbows for A1 was $135.66^{\circ} \pm 8.46^{\circ}$ during practice and $136.62^{\circ} \pm$ $8.66^{\circ}$ (left-handed batter) and $136.82^{\circ} \pm 7.79^{\circ}$ (right-handed batter) during a game, indicating no significant differences among the three conditions. The angle of the shoulders and elbows for A2 was $119.73^{\circ} \pm 12.58^{\circ}$ during practice and $120.37^{\circ} \pm 13.57^{\circ}$ (left-handed batter) and $121.96^{\circ} \pm 13.01^{\circ}$ (right-handed batter) during a game; there was a significant difference $(P=0.017)$; the obtained values were lower in $\mathrm{C} 1$ than in $\mathrm{C} 3$.

\section{DISCUSSION}

A baseball game begins with the pitching of a ball by a pitcher, and the pitcher plays a relatively substantial role compared with other players in baseball. Ball pitching by a pitcher not only involves the use of the arms, but also more than $50 \%$ of the force is generated by the legs and back, which also transfer the force to the hands. There are various factors in determining conditions for the biomechanics of baseball (Davis et al., 2009; Fleisig et al., 2011), and distinct conditions influence the pitching motions of a pitcher.

By establishing various conditions for pitching in baseball, the moving distances and angles of the joints were analyzed in this report. The moving distances of $\mathrm{D} 1$ was the shortest in $\mathrm{C} 3$, and the inclination angle of A2 was the smallest in C1. D1 was determined to lengthen the elbow joint depending on the pitching conditions, and A2 tended to lean the torso towards the nonpitching arm to release the ball during pitching. These motions are thought to decrease the risk for a dead ball and set the ball on a diagonal path that leads the ball away from the batter's bat. Alterations in the elbow joint affect the rotation of a ball (Elliott et al., 1986), and stability of these joints upon valgus stress depends on their flexion angles (Morrey and An, 1983; Regan et al., 1991). Further, injuries to the elbow joint, which frequently occur in high school baseball players, are associated with improper pitching motions as well as overuse (Lim, 2007), and considering the same pitching motions during practice, abrupt changes in the angle of the elbows can translate into imperfect pitching. The stress caused by repetitive improper pitching motions during baseball games potentially affects elbow injuries in high school pitchers.

$\mathrm{C} 3$ showed the lowest $\mathrm{D} 5 /$ height $(\mathrm{HT})$, while $\mathrm{C} 1$ had the shortest moving distance of D7/HT. D5/HT and D7/HT allowed stepping forward at the point of BR depending on the pitching conditions and spreading of the legs apart even further. Based on the association between the changes in the pitching motions and injuries during proper pitching, the center of gravity of the body transfers towards the target in a smooth manner, and the impact on the arm changes depending on the placement and location of the feet (Sain and Andrews, 1985). Further, if the landing foot faces left, the torso opens up prematurely, leading to excessive stress on the shoulder and elbow joints (Meister, 2000). Therefore, excessive adduction/abduction of the shoulder following the movement of the landing foot of the pitcher during a baseball game can increase the risk for injuries.

Taken together, these findings suggest that the pitching motions differ depending on the pitching conditions and the location of the batter, and these inconsistencies in the pitching motions likely elevate the risk for injuries. To prevent injuries in high school pitchers, it is important to establish limitations in the pitch numbers and innings and provisions of sufficient rest and teaching programs regarding pitching techniques (Mcfarland and Ireland, 2003). Thus, proper pre-game stretching and regular muscle-strengthening exercises are necessary for the prevention of pitching-related injuries during a baseball game (Park, 2003), and it would be beneficial to prevent injuries to simulate game-like 
conditions during practice and develop practice methods that minimize inconsistencies in a pitcher's pitching motions.

\section{CONFLICT OF INTEREST}

No potential conflict of interest relevant to this article was reported.

\section{ACKNOWLEDGMENTS}

This work was supported by the National Research Foundation of Korea Grant funded by the Korean Government (NRF2017S1A5B8066096).

\section{REFERENCES}

Albright JA, Jokl P, Shaw R, Albright JP. Clinical study of baseball pitchers: correlation of injury to the throwing arm with method of delivery. Am J Sports Med 1978;6:15-21.

Braatz JH, Gogia PP. The mechanics of pitching. J Orthop Sports Phys Ther 1987;9:56-69.

Collins CL, Comstock RD. Epidemiological features of high school baseball injuries in the United States, 2005-2007. Pediatrics 2008;121:11811187.

Conte S, Requa RK, Garrick JG. Disability days in major league baseball. Am J Sports Med 2001;29:431-436.

Cowderoy GA, Lisle DA, O'Connell PT. Overuse and impingement syndromes of the shoulder in the athlete. Magn Reson Imaging Clin N Am 2009;17:577-593, v.

Davis JT, Limpisvasti O, Fluhme D, Mohr KJ, Yocum LA, Elattrache NS, Jobe FW. The effect of pitching biomechanics on the upper extremity in youth and adolescent baseball pitchers. Am J Sports Med 2009;37: 1484-1491.

Dick R, Sauers EL, Agel J, Keuter G, Marshall SW, McCarty K, McFarland E. Descriptive epidemiology of collegiate men's baseball injuries: National Collegiate Athletic Association Injury Surveillance System, 19881989 through 2003-2004. J Athl Train 2007;42:183-193.

Dun S, Kingsley D, Fleisig GS, Loftice J, Andrews JR. Biomechanical comparison of the fastball from wind-up and the fastball from stretch in professional baseball pitchers. Am J Sports Med 2008;36:137-141.

Elliott B, Grove JR, Gibson B, Thurston B. A three-dimensional cinematographic analysis of the fastball and curve pitches in baseball. Int $J$ Sport Biomech 1986;2:20-28.

Escamilla RF, Barrentine SW, Fleisig GS, Zheng N, Takada Y, Kingsley D, Andrews JR. Pitching biomechanics as a pitcher approaches muscular fatigue during a simulated baseball game. Am J Sports Med 2007;35: 23-33.

Fleisig GS, Barrentine SW, Zheng N, Escamilla RF, Andrews JR. Kinematic and kinetic comparison of baseball pitching among various levels of development. J Biomech 1999;32:1371-1375.

Fleisig GS, Bolt B, Fortenbaugh D, Wilk KE, Andrews JR. Biomechanical comparison of baseball pitching and long-toss: implications for training and rehabilitation. J Orthop Sports Phys Ther 2011;41:296-303.

Fleisig GS, Escamilla RF, Andrews JR, Matsuo T, Satterwhite Y, Barrentine SW. Kinematic and kinetic comparison between baseball pitching and football passing. J Appl Biomech 1996;12:207-224.

Huang YH, Wu TY, Learman KE, Tsai YS. A comparison of throwing kinematics between youth baseball players with and without a history of medial elbow pain. Chin J Physiol 2010;53:160-166.

Hutchinson MR, Ireland ML. Overuse and throwing injuries in the skeletally immature athlete. Instr Course Lect 2003;52:25-36.

Jobe FW, Moynes DR, Tibone JE, Perry J. An EMG analysis of the shoulder in pitching. A second report. Am J Sports Med 1984;12:218-220.

Jobe FW, Tibone JE, Perry J, Moynes D. An EMG analysis of the shoulder in throwing and pitching. A preliminary report. Am J Sports Med 1983; 11:3-5.

Keeley DW, Oliver GD, Dougherty CP. Shoulder kinematics during pitching: comparing the slide step and traditional stretch deliveries. Hum Mov Sci 2012;31:1191-1199.

Lim SK. Review of ulnar collateral ligament injuries and prevention in baseball players. J Coach Dev 2007;9:65-80.

Lyman S, Fleisig GS, Andrews JR, Osinski ED. Effect of pitch type, pitch count, and pitching mechanics on risk of elbow and shoulder pain in youth baseball pitchers. Am J Sports Med 2002;30:463-468.

Matsuo T, Escamilla RF, Fleisig GS, Barrentine SW, Andrews JR. Comparison of kinematic and temporal parameters between different pitch velocity groups. J Appl Biomech 2001;17:1-13.

McFarland EG, Ireland ML. Rehabilitation programs and prevention strategies in adolescent throwing athletes. Instr Course Lect 2003;52: $37-42$.

Meister K. Injuries to the shoulder in the throwing athlete. Part one: Biomechanics/pathophysiology/classification of injury. Am J Sports Med 2000;28:265-275.

Morrey BF, An KN. Articular and ligamentous contributions to the stability of the elbow joint. Am J Sports Med 1983;11:315-319.

Park JY. Conservative treatment of throwing injury. J Korean Orhop Sports Med 2003;2:127-135.

Parks ED, Ray TR. Prevention of overuse injuries in young baseball pitchers. Sports Health 2009;1:514-517.

Posner M, Cameron KL, Wolf JM, Belmont PJ Jr, Owens BD. Epidemiolo- 
gy of Major League Baseball injuries. Am J Sports Med 2011;39:16761680.

Queale WS, Bennett TD, Smith GS, McFarland EG. Epidemiology of college baseball injuries. Med Sci Sports Exerc 2001;33:S81.

Regan WD, Korinek SL, Morrey BF, An KN. Biomechanical study of ligaments around the elbow joint. Clin Orthop Relat Res 1991;(271):170179 .

Rizio L, Uribe JW. Overuse injuries of the upper extremity in baseball. Clin Sports Med 2001;20:453-468.

Sain J, Andrews JR. Proper pitching techniques: injuries to the throwing arm. Philadelphia (PA): WB Saunders; 1985. p. 30-37.

Stodden DF, Fleisig GS, McLean SP, Andrews JR. Relationship of biome- chanical factors to baseball pitching velocity: within pitcher variation. J Appl Biomech 2005;21:44-56.

Whiteley R. Baseball throwing mechanics as they relate to pathology and performance - a review. J Sports Sci Med 2007;6:1-20.

Wright RW, Steger-May K, Klein SE. Radiographic findings in the shoulder and elbow of Major League Baseball pitchers. Am J Sports Med 2007;35:1839-1843.

Yamada Y, Yamashita D, Yamamoto S, Matsui T, Seo K, Azuma Y, Kida Y, Morihara T, Kimura M. Whole-body and segmental muscle volume are associated with ball velocity in high school baseball pitchers. Open Access J Sports Med 2013;4:89-95. 